\title{
El alojamiento privado turístico en España y Portugal: Comparativa regulatoria e influencia de su fiscalidad
}

\section{Private accommodation for tourists in Spain and Portugal: Comparative analysis and influence of tax regime}

\author{
Maria del Carmen Pastor del Pino \\ Facultad de Ciencias de la Empresa, Universidad Politécnica de Cartagena, España \\ carmen.pino@upct.es
}

Lurdes Varela

Escola Superior de Gestão, Hotelaria e Turismo da Universidade do Algarve, Portugal

mlvarela@ualg.pt

\section{Resumen}

\begin{abstract}
El alojamiento turístico como toda instalación que ocasionalmente ofrece plazas para que el turista pueda pasar la noche presenta una gran dificultad de delimitación de las tipologías o unidades de alojamiento que lo pueden conformar en los distintos países, y en consecuencia en la comparativa de su regulación. Partiendo de esta dificultad, el propósito del presente trabajo es el de analizar los regímenes jurídicos sectoriales que regulan el alojamiento privado a turistas en Portugal y España para concretar sus semejanzas y diferencias, intentando alcanzar un concepto homólogo que nos permita efectuar la posterior comparativa tributaria y llegar a las oportunas conclusiones. Se trata en definitiva de comprobar si las regulaciones fiscales de cada país presentan o no en el plano teórico una potencial capacidad para estimular tales comportamientos en su configuración actual.
\end{abstract}

Palabras clave: Alojamiento turístico; alojamiento privado; Portugal y España; regulación sectorial; régimen tributario.

\begin{abstract}
Tourist accommodation, like any facility that regularly or occasionally offers a place for tourists to spend the night, is difficult to categorise in terms of the types or units of accommodation that can be offered in different countries, and consequently in the comparison of its regulation. Starting from this difficulty, the purpose of this paper is to analyse the legal, sectoral and tax regimes of Portugal and Spain in the field of temporary private tourist accommodation, to identify their similarities and differences, and to attempt to reach a homologous concept that permits a subsequent tax comparison in order to reach appropriate conclusions.
\end{abstract}

Keywords: temporary tourist accommodation; private accommodation; Portugal and Spain; sectoral regulation; tax regime.

Dos Algarves: A Multidisciplinary e-Journal, 34-2019.

ISBN 2182-5580 @ ESGHT - University of the Algarve, Portugal. 


\section{Resumo}

O alojamento turístico, como qualquer serviço que ocasionalmente oferece locais para os turistas passarem a noite, apresenta uma grande dificuldade na delimitação dos tipos ou unidades de alojamento em diferentes países, e consequentemente na comparação da sua regulação. Com base nessa dificuldade, o objectivo deste artigo é analisar os regimes legais, setoriais e fiscais, de Portugal e Espanha no domínio do alojamento turístico privado temporário, para identificar as suas semelhanças e diferenças, tentando chegar a um conceito de contrapartida que permita a comparação de impostos subsequentes e chegar a conclusões apropriadas. Em última análise, tratase de verificar se os regulamentos fiscais de cada país apresentam, ou não, ao nível teórico, uma capacidade potencial para estimular tais comportamentos

Palavras-clave: Alojamento turístico; alojamiento particular; Portugal e Espanha; regulação setorial; regime tributário.

\section{Introducción}

La Organización Mundial del Turismo utiliza la clasificación de alojamiento turístico colectivo y privado para referirse a realidades que presentan rasgos comunes pero diferentes sujetos de intervención. En el primero caso, estamos ante establecimientos de hospedaje que prestan servicios de alojamiento, contando con un número de plazas superior a un mínimo determinado, para colectivos de personas que sobrepasan a una sola unidad familiar, disponiendo, aunque no tenga fines de lucro, de una administración de tipo comercial común para todas las plazas de un mismo establecimiento. ${ }^{1}$ Este tipo de establecimientos consta principalmente de hoteles y asimilados, y otros establecimientos colectivos especializados. Bajo la denominación de alojamiento privado se agruparían entonces los restantes tipos de alojamiento turístico que, por tener carácter específico, no responden a la definición de "establecimiento". Así, englobaría aquél que ofrece plazas en número limitado en alquiler o gratuitamente, de modo que cada unidad de alojamiento sería independiente (habitación o vivienda) y estaría ocupada por turistas (por semanas, quincenas o meses) o por sus propietarios (vivienda secundaria o de vacaciones), comprendiendo tanto el supuesto del alquiler a particulares, familias o agencias profesionales (apartamentos, villas, casas, chalets y otros alojamientos alquilados en totalidad, temporalmente, o bien habitaciones alquiladas en casas particulares), como el de la cesión gratuita a los huéspedes.

El presente trabajo se centra en el alojamiento privado, en concreto en el consistente en el alquiler temporal de unidades de alojamiento con fines turísticos, con el objetivo de analizar las diferencias existentes en este tipo de alojamientos en dos países eminentemente turísticos, como España y Portugal, atendiendo a sus regulaciones sectorial y tributaria. A tal efecto, el trabajo se estructura en dos partes: en la primera se analiza el régimen jurídico sectorial del alojamiento privado turístico temporal existente en España y en Portugal, para concretar sus semejanzas y diferencias. Efectuado este análisis y tras alcanzar una misma realidad comparativa, se revisa a continuación el régimen tributario previsto en cada país, para realizar finalmente un estudio de caso que ilustre las diferencias regulatorias y permita obtener las oportunas conclusiones.

\footnotetext{
${ }^{1}$ Organización Mundial del Turismo, 2008: 21.
} 


\section{Encuadramiento jurídico sectorial y tributario del alojamiento turístico privado en España y Portugal}

\subsection{España}

El régimen jurídico del alojamiento temporal turístico privado en España resulta complejo de analizar tanto en su revisión aislada como en la conjunta con otro país como Portugal. Y lo es, porque España presenta una doble peculiaridad que se entrelaza. Por un lado, la de su estructura territorial y distribución competencial y regulatoria entre Estado y Comunidades Autónomas, fundamental en la materia que nos ocupa. Por otro, porque a diferencia de la regulación de este tipo de alojamientos en Portugal, en España no existe un único concepto que recoja y defina este tipo de alojamientos, sino tantos como regulaciones autonómicas que los prevean, dificultando extraordinariamente su revisión. Analicemos lo expuesto.

\subsubsection{Regulación jurídica sectorial}

La regulación del alojamiento privado de uso turístico en su modalidad de alquiler de viviendas experimentó en España un importante cambio en 2013. Hasta entonces los contratos de hospedaje o alojamiento y de arrendamiento de temporada que lo instrumentaban se regulaban por la normativa estatal, en preceptos aislados del Código Civil (arts. 1783 y 1784, 1922 y 1967) y en la Ley de Arrendamientos Urbanos (Ley 29/1994, de 24 de noviembre, LAU), residiendo la diferencia entre ambos contratos en que en los primeros existía junto a la cesión de uso de un bien un contrato de arrendamiento de servicios (los servicios propiamente turísticos), mientras en los segundos simplemente se producía la mera cesión del uso del bien. Esta situación regulatoria uniforme se modifica en parte tras la aprobación de la Ley 4/2013, de 4 de junio, de medidas de flexibilización y fomento del mercado del alquiler de viviendas, al quedar excluido de la regulación de la LAU: "la cesión temporal de uso de la totalidad de una vivienda amueblada y equipada en condiciones de uso inmediato, comercializada o promocionada en canales de oferta turística y realizada con finalidad lucrativa, cuando está sometida a un régimen específico derivado de su normativa sectorial" (art. 5 e). Con esta exclusión se trataba de evitar que: "la extensión del uso del alojamiento privado para fines turísticos (...) pudiera dar cobertura a situaciones de intrusismo y competencia desleal, en contra de la calidad de los destinos turísticos" (Exposición de Motivos de la propia Ley). De acuerdo con ello, los alquileres que reunieran los requisitos referidos quedarían regulados por su "normativa sectorial específica", entendiéndose por tal la normativa autonómica sobre ordenación turística. ${ }^{2}$

\footnotetext{
${ }^{2}$ Como dispone el $\operatorname{art}^{\circ} \cdot 148.1 .18^{\circ}$ de la Constitución Española, corresponde a las Comunidades Autónomas (CCAA) la competencia en materia de promoción y ordenación del turismo. De este modo las distintas CCAA han asumido esta competencia en sus diferentes Estatutos de Autonomía, aprobando la correspondientes Leyes sobre Ordenación Turística, si bien indicando que se aplicará en su caso la normativa estatal de forma supletoria. Conforme a ello, y como indica el propio art. 5 e) Ley 4/2013, de no existir normativa específica autonómica sobre ordenación turística, se le seguirá aplicando a todos los arrendamientos de temporada el régimen previsto en la LAU, que no sufre modificaciones. De este modo, los contratos de arrendamiento de temporada quedarán regulados por la LAU en dos situaciones: cuando éstos no se refieran a "vivienda amueblada y equipada en condiciones de uso inmediato, comercializada o promocionada en canales de oferta turística y realizada con finalidad lucrativa"; o, cuando éstos no estén sometidos "a un régimen específico derivado de su normativa sectorial", resultando en caso contrario aplicable las normativas autonómicas en materia de ordenación del
} 
Esta modificación tuvo a partir de entonces extraordinarias consecuencias. Y es que si anteriormente todos los arrendamientos de temporada quedaban sujetos a la normativa estatal, con la consiguiente libertad de las partes para la contratación y sin establecimiento de requisitos de comunicación previa a la Administración, a partir de entonces y en adelante, aquéllos que reunieran las características indicadas quedarían sujetos a las correspondientes normativas autonómicas, y en consecuencia sujetos al cumplimiento de los diferentes requisitos administrativos que en cada caso se establecieran. De acuerdo con lo expuesto, y existiendo en España 17 CCAA, se han ido sucediendo en el tiempo diferentes regulaciones autonómicas, de modo que a 2018 la mayoría dispone de normativas específicas en vigor reguladoras de viviendas destinadas a un uso o fin turístico, teniendo previsto hacerlo en breve las restantes. ${ }^{3}$

Esta diseminada regulación temporal ha llevado aparejado sin embargo un importante problema de heterogeneidad. ${ }^{4} \mathrm{Y}$ es que conforme a su capacidad, necesidad e interés, cada CCAA ha ido configurando de forma absolutamente dispar, tanto el propio objeto de regulación, como los diferentes requisitos administrativos de registro o de control, pudiendo afirmar que no existe uniformidad ni siquiera en la propia denominación del objeto regulatorio, como tampoco la hay en la caracterización o las exigencias administrativas previstas en cada caso..$^{5}$ El régimen jurídico en España de este tipo de viviendas destacaría así por dos notas: su falta de homogeneidad (faltando al cumplimiento del principio de unidad de mercado en la

turismo que así lo contemplen. Por su parte, los contratos de alojamiento u hospedaje se regulan de forma conjunta por la normativa estatal civil, en sus aspectos privados, y por las autonómicas de turismo en lo referido a sus aspectos administrativos. Respecto a la relación y problemas surgidos entre ambas realidades (Verdera, 2009: 3-19).

${ }^{3}$ Disponen de normativa específica reguladora de viviendas destinadas a uso o con fin turístico 13 CCAA: Andalucía, Aragón, Asturias, Baleares, Canarias, Cantabria, Castilla la Mancha, Castilla León, Cataluña, Com. Valenciana, La Rioja, Madrid y País Vasco. La más reciente en aprobarla ha sido hasta la fecha, Castilla la Mancha, mediante Decreto 36/2018, de 29 de mayo, por el que se establece la ordenación de los apartamentos turísticos y las viviendas de uso turístico. Por lo demás, Galicia, Extremadura y Murcia, prevén su regulación, existiendo proyectos aun no aprobados. Navarra regula la denominada "vivienda turística", pero como modalidad de apartamento turístico (art. 3 Decreto foral 230/2011, de 26 de octubre)

${ }^{4}$ Así (Román, Pavlova, Nieto \& Bonillo, 2017)

${ }^{5}$ No existe un concepto uniforme objeto de regulación. Respecto a su denominación es mayoritario el empleo de "vivienda de uso turístico" (en Andalucía, Cataluña, Madrid o Baleares), aunque también se utiliza el de "viviendas vacacionales" (Canarias o Asturias) o "viviendas turísticas" (Comunidad Valenciana o Navarra). Los requisitos previstos también son de lo más diverso, encontrándonos regulaciones autonómicas que, por ejemplo: exigen la cesión total del inmueble (Asturias o Cataluña) o que permiten también la parcial (Andalucía); que permiten todo tipo de viviendas (pisos, chalets, cuevas., así, Navarra.) o sólo las de determinado tipo (Asturias o Baleares); que pueden ser explotadas por el propietario directamente o por un tercero, con o sin requisitos adicionales (Cataluña o Com. Valenciana), o sólo lo permiten si son gestionadas por una empresa (Cantabria); o, que establecen limitaciones respecto a la duración mínima o máxima de la estancia (Andalucía, no superior a dos meses de forma continuada por un mismo usuario; Cataluña, estancia por tiempo continuo igual o inferior a 31 días; en Madrid, por ejemplo, la obligatoriedad de contratación del alojamiento por un periodo igual o superior a cinco días que venía prevista en su normativa ha sido declarado nula por S 292/2016, del TSJ Madrid de 31 mayo, núm. 1165/2014; o la Comunidad Valenciana, en la que no se prevé limitación del tiempo contratado; ver (Martín-Faba, 2016). Todo ello sin perjuicio de las importantes diferencias existentes también respecto a otras cuestiones relevantes como su clasificación, el régimen sancionador, o las distintas exigencias en aspectos de tramitación, comercialización o explotación de las viviendas. 
normativa turística que les afecta); y, su carácter limitado, no abarcando la totalidad del fenómeno que las engloba. ${ }^{6}$ De este modo podría decirse que hasta el momento la normativa actual ha supuesto más un intento de priorizar el afloramiento de esta oferta, que una firme decisión de regulación transversal de todas las implicaciones jurídicas, económicas y sociales que conlleva.?

\subsubsection{Régimen tributario aplicable}

Destacadas las principales notas características del actual régimen jurídico en España de este tipo de viviendas, referidas desde ahora como "viviendas de uso turístico" por ser la denominación más empleada, debemos centrarnos en el régimen tributario que les es aplicable. Para ello se han de efectuar dos consideraciones previas que permiten concretar el objeto de estudio y la forma de llevarlo a cabo. España conforme a su estructura territorial dispone de tres niveles de competencia tributaria: estatal, autonómica y local o municipal, con capacidad impositiva (propia y/o cedida) relacionada con la adquisición, tenencia, transmisión y obtención de rendimientos relacionados con inmuebles o viviendas. Sin perjuicio de los diferentes gravámenes que pudieran soportar el titular o propietario de la vivienda, nos limitaremos en el presente trabajo a revisar los aspectos relacionados con la obtención de rendimientos derivados de la cesión temporal de uso de las viviendas destinadas a fines turísticos, teniendo en cuenta que un estudio del régimen tributario aplicable requeriría de la revisión conjunta de todos los gravámenes concurrentes. ${ }^{8}$ Delimitado el alcance de la revisión tributaria cabe indicar respecto a la forma de realización del análisis, que éste se efectuará atendiendo a la calificación tributaria atribuida en cada caso al rendimiento obtenido, al ser éste el elemento de diferenciación principal entre los regímenes de los dos países, así como lógicamente atendiendo a la diferente naturaleza jurídica del titular de la vivienda.

Pues bien, el régimen tributario previsto en el ordenamiento tributario español para los rendimientos derivados del alquiler o cesión de uso de una vivienda varía según conlleve o no la realización de una actividad económica, según la naturaleza jurídica de su titular, y según su residencia, debiendo destacar como aspecto relevante que no existe en principio especialidad alguna por el hecho de tratarse de viviendas destinadas de forma concreta a un uso turístico.

\footnotetext{
${ }^{6}$ Sobre esta falta de homogeneidad y sus consecuencias (Herrero, 2017).

${ }^{7}$ La falta de regulación transversal en este ámbito se intenta suplir con estudios doctrinales donde se contemplan especialmente los aspectos relacionados con las repercusiones civiles y administrativas. En este sentido, y con relación tanto a España como a Portugal (Asociación Española de Contabilidad y Administración de Empresas, 2014).

${ }^{8}$ Así, por su tenencia, y como tributo municipal, el particular (persona física o jurídica) titular de la vivienda de uso turístico está sujeto al Impuesto sobre Bienes Inmuebles (IBI) (arts. 60 a 77 del Real Decreto Legislativo 2/2004, de 5 de marzo, por el que se aprueba el texto refundido de la Ley Reguladora de las Haciendas Locales, en adelante TRLHL). De igual naturaleza municipal, y por la mera titularidad en el ejercicio de una actividad económica se devengaría el Impuesto sobre Actividades Económica (IAE), tributo que grava el inicio de cualquier actividad empresarial, profesional o artística por persona física o jurídica en territorio español. De este modo, dentro de las tarifas del IAE se encuentra el alojamiento turístico extrahotelero epígrafe 685 y en el 686 la explotación de apartamentos privados. En cualquier caso, es importante destacar que están exentos de pago: siempre las personas fiscas, y además las jurídicas cuando el importe neto cifra de negocios sea inferior a 1 millón euros. Pero han de presentar en cualquier caso la declaración de alta y de baja (modelo 036- 037), así como la modificación de datos fiscales (arts. 78 a 91 del TRLHL). Y todo ello además sin detenernos en este trabajo en las obligaciones derivadas del Impuesto sobre el Valor Añadido.
} 
De acuerdo con ello y atendiendo al régimen general de tributación, si el propietario de la vivienda cedida es una persona física residente en territorio español que limita su actuación por sí mismo a la cesión del uso temporal del inmueble, el rendimiento se califica por la normativa tributaria como rendimiento de capital inmobiliario del Impuesto sobre la Renta de las Personas Físicas (arts. 21 a 23 Ley 35/2006, de 28 de noviembre, del Impuesto sobre la Renta de las Personas Físicas y de modificación parcial de las leyes de los Impuestos sobre Sociedades, sobre la Renta de no Residentes y sobre el Patrimonio (en adelante, LIRPF). ${ }^{9}$ Y ello tanto si la cesión de uso la realiza directamente el propietario, como si la efectúa una empresa gestora con la que se hubiera pactado la intermediación en la gestión con el cliente, o a la que se le hubiera cedido previamente su explotación. La empresa gestora por su parte tributará por el importe obtenido de la cesión, según se trate de una persona física o jurídica: como renta de actividad económica en el IRPF o como renta sujeta al Impuesto sobre Sociedades (IS), lo que ocurrirá de igual modo si el propietario del inmueble fuese una persona jurídica, y a las que más tarde nos referiremos.

Respecto a la cuantificación del gravamen cabe señalar que los rendimientos netos de capital inmobiliario se integrarán en la base imponible general junto a los netos de rendimientos de trabajo, capital mobiliario del art. 25. 4, actividades económicas, y ganancias y pérdidas que no derivan de transmisión, aplicando sobre la cuantía total resultante compensada las correspondientes escalas de gravamen estatal y autonómica (arts. 47 a 49 y 63 y 74 LIRPF). El neto de capital inmobiliario se obtiene deduciendo de los ingresos obtenidos, los gastos "necesarios para la obtención de los ingresos" y la amortización por su depreciación efectiva, sin que quepa reducción al no darse ninguna de las hipótesis contempladas para ello. ${ }^{10}$

\footnotetext{
9 El art. 9.1 de la Ley 35/2006, del IRPF establece como criterios para entender que un contribuyente tiene su residencia habitual en territorio español: a) el criterio de la permanencia más de 183 días, durante el año natural, en territorio español; o, b) que radique en España el núcleo principal o la base de sus actividades o intereses económicos, de forma directa o indirecta. Cuando, de acuerdo con los criterios anteriores, resida habitualmente en España el cónyuge no separado legalmente y los hijos menores de edad que dependan de aquél, existirá presunción iuris tantum de residencia). Por lo demás, y como indica el art. 22 de la LIRPF tendrán la consideración de rendimientos íntegros de capital inmobiliario, los procedentes de la titularidad de bienes inmuebles rústicos y urbanos o de derechos reales que recaigan sobre ellos, "todos los que se deriven del arrendamiento o de la constitución o cesión de derechos o facultades de uso o disfrute sobre aquéllos, cualquiera que sea su denominación o naturaleza". Por otro lado, hay que ampliar el punto de vista de los sujetos a gravamen, para incorporar el turismo colaborativo: la actual legislación regula la actividad turística desde el punto de vista de la condición empresarial pero no desde la nueva figura del prosumidor, a quienes habría que considerar en ocasiones verdaderos empresarios, con obligaciones tributarias, al estar realizando entregas de bienes o prestaciones de servicios con el fin de obtener ingresos continuados en el tiempo. El nuevo turista es un sujeto activo que se convierte asimismo en un promotor turístico. En este sentido, (RecioRamírez, 2016).

${ }^{10}$ Indica el art. 23.1.a) de la LIRPF que son gastos deducibles "necesarios para la obtención de los ingresos", en proporción al tiempo en que ha sido cedida su uso: los intereses de los capitales ajenos invertidos en la adquisición o mejora del bien; los gastos de conservación y reparación; los tributos y recargos no estatales (por ejemplo, el IBI) y tasas y recargos estatales; las cantidades devengadas por terceros por servicios personales (portería, administración...); los saldos de dudoso cobro; y la amortización del inmueble y de los muebles incluidos en él (en cuantía que no exceda del 3 por ciento sobre el mayor de los valores de adquisición o catastral). Por lo demás, no proceden las reducciones previstas en los apartados 2 y 3 del art. 23.2, del 60 por ciento por vivienda habitual del inquilino, y del 30 por ciento por rendimientos irregulares (arts. 13-15 del Real Decreto 439/2007, por el que se aprueba el Reglamento del IRPF). Pero sí habrá que declarar, si no es la vivienda habitual, una "Imputación de
} 
Por lo demás, si el titular de la vivienda utilizara de forma simultánea ésta como residencia propia, además de alquilarla (algunos días del año o parte de la misma), parece que podría seguir disfrutando del régimen transitorio de la deducción por adquisición o inversión en vivienda habitual previsto para adquisiciones anteriores a 1 de enero de 2013 (Disposición Transitoria $18^{\text {a }}$ de la LIRPF), ${ }^{11}$ debiendo aplicarse el beneficio fiscal eso sí en proporción a la superficie del bien inmueble que se utiliza como vivienda habitual, y no por la parte de la vivienda que se encuentra alquilada.

La segunda posibilidad que debemos contemplar es que el propietario de la vivienda cedida, persona física residente en territorio español, además de la cesión del uso temporal del inmueble preste servicios propios de la industria hotelera (tales como restaurante, limpieza, lavado de ropa y otros análogos). En este caso, el rendimiento se califica por la normativa tributaria como rendimiento de actividad económica, al intervenir el contribuyente en la producción o distribución de bienes y servicios, mediante la ordenación por cuenta propia de medios de producción y de recursos humanos o de uno de ambos (art. 27 LIRPF). ${ }^{12}$ El apartado 2 del mismo precepto delimita además que el arrendamiento de inmuebles se realiza como actividad económica, "únicamente cuando para la ordenación de ésta se utilice, al menos, una persona empleada con contrato laboral y a jornada completa." A este respecto cabe indicar que aunque la finalidad de esta concreción es establecer unos requisitos mínimos para que la actividad de arrendamiento de inmuebles pueda entenderse como una actividad empresarial (requisitos que inciden en la necesidad de una infraestructura mínima y de una organización de medios empresariales, para que esta actividad tenga tal carácter), su exigencia resulta en cierto modo arbitraria y confusa, como lo demuestran las numerosas contestaciones a consultas tributarias planteadas por los contribuyentes, las resoluciones administrativas o los pronunciamientos jurisprudenciales dictados para precisar o descartar los supuestos en que se cumplen estas circunstancias. ${ }^{13}$ En cualquier caso, y mientras no se modifiquen los términos

renta inmobiliaria" por el tiempo que esté vacía, computándose ésta en la cuantía del 2 por ciento o 1,1 por ciento del valor catastral o del valor catastral revisado respectivamente (art. 85 LIRPF).

${ }^{11}$ El hecho de alquilar de forma esporádica y puntal a través de plataformas online no debería impedir la aplicación de esta deducción de forma transitoria, siempre que reúna los requisitos previstos en su momento para aplicársela (ser efectivamente vivienda habitual, es decir, aquella que el contribuyente resida durante un plazo continuado de tres años, o que, a pesar de no haber transcurrido dicho plazo, concurran circunstancias que necesariamente exijan el cambio de vivienda, como celebración de matrimonio, separación matrimonial, traslado laboral, obtención de primer empleo o de empleo más ventajoso u otras análoga. Disposición Adicional 23a LIRPF). Así, también (Ruíz: 2017: 67).

${ }^{12}$ El artículo 27 de la LIRPF establece, en su apartado 1, que "se considerarán rendimientos íntegros de actividades económicas aquellos que, procediendo del trabajo personal y del capital conjuntamente, o de uno solo de estos factores, supongan por parte del contribuyente la ordenación por cuenta propia de medios de producción y de recursos humanos o de uno de ambos, con la finalidad de intervenir en la producción o distribución de bienes o servicios".

${ }^{13}$ Exige el precepto que exista una persona empleada para gestionar la actividad del arrendamiento que debe tener un contrato calificado de laboral, a jornada completa, y que preste servicios relacionados con la gestión de dicha actividad. Cada uno de estos requisitos ha suscitado problemas relacionados con la naturaleza laboral o no del contrato, por ejemplo, a familiares, socios o administradores (consultas de la Dirección General de Tributos V0632-13, V1364-06, o V2127-99), el cómputo efectivo de la jornada completa, o la naturaleza de los servicios de gestión de la actividad (Sentencia del Tribunal Superior de Justicia de Murcia de 10 de marzo de 2016, o consultas V1330-16, Vo660-16, o V3549-15). Se plantea incluso la duda del carácter del propio requisito referido como, necesario y de mínimos, o simplemente probatorio: $\mathrm{y}$ así mientras distintos pronunciamientos jurisprudenciales lo consideran como una mera evidencia de actividad económica, que no obstante puede ser desvirtuada o probada por cualquier otro 
del referido precepto, la confusión se mantendrá, pudiendo darse además la paradójica situación de sujetos titulares de viviendas cedidas para un uso turístico no considerados como empresarios o profesionales a efectos de IRPF, por no reunir el requisito referido, pero que sí lo pudieran ser a efectos del Impuesto sobre el Valor Añadido, por ser arrendadores de inmuebles y venir así previsto en su normativa reguladora. ${ }^{14}$

Respecto a la cuantificación de las rentas de actividad económica en el IRPF cabe señalar que no existe ninguna especialidad aplicable a los rendimientos provenientes de estos alquileres temporales de destino turístico, resultando de aplicación los regímenes normales de cálculo en estimación directa normal o directa simplificada, y quedando excluida la estimación objetiva. ${ }^{15}$ En cualquier caso, y antes de referir algunas notas de tales regímenes precisaremos, por la remisión que la LIRPF efectúa a la del Impuesto sobre Sociedades para aplicar tales regímenes de cálculo, que tampoco existe especialidad regulatoria alguna si el titular es una persona jurídica residente en territorio español, cuyos ingresos tributarán en el Impuesto sobre Sociedades (IS), o persona física o jurídica no residente en territorio español, en cuyo caso deberá satisfacerse el Impuesto sobre la Renta de No Residentes, y cuya normativa tampoco prevé ninguna especificidad. ${ }^{16}$ De acuerdo con ello, los rendimientos netos de actividad económica calculados en estimación directa normal conforme a la normativa contable y los ajustes extracontables o fiscales oportunos, o simplificada, con las limitaciones de gasto preceptivas, tributarán al tipo general, sin perjuicio de los oportunos beneficios fiscales previstos por la normativa del impuesto que pudieran serles aplicables. ${ }^{17}$

medio admitido en Derecho (sentencias de la Audiencia Nacional de 29 de enero de 2009, o de 14 de febrero de 2013.o sentencia del Tribunal Supremo de 16 de abril de 2012), la doctrina administrativa lo considera en ocasiones como un requisito necesario y mínimo (consultas V3048-16, 3017-16), precisando en otros casos supuestos en los que pese a existir el requisito no sería actividad económica (así, por ejemplo, por la "escasa envergadura de la actividad", en resoluciones del Tribunal Económico Central de 30 de junio de 2010, 02 de febrero de 2012).

${ }^{14}$ En el IVA se reputan empresarios o profesionales "quienes realicen una o varias entregas de bienes o prestaciones de servicios que supongan la explotación de un bien corporal o incorporal con el fin de obtener ingresos continuados en el tiempo. En particular, tendrán dicha consideración los arrendadores de bienes" (artículo 5 de la Ley 37/1992, del IVA).

${ }^{15}$ El art. 28 de La LIRPF se remite a la normativa del Impuesto sobre Sociedades para efectuar la cuantificación de las rentas de actividades económicas. Precisa en su art. 30 que la determinación de tales rendimientos se efectuará, con carácter general, por el método de estimación directa, normal o simplificada. Esta última se aplicará para determinadas actividades económicas cuyo importe neto de cifra de negocios, para el conjunto de actividades desarrolladas por el contribuyente, no supere los 600.000 euros en el año inmediato anterior, salvo que renuncie a su aplicación. En los supuestos de renuncia o exclusión de la modalidad simplificada, el contribuyente determinará el rendimiento neto de todas sus actividades económicas por la modalidad normal durante los tres años siguientes, en las condiciones que reglamentariamente se establezcan.

${ }^{16}$ El IS está regulado por la Ley 27/2014, de 27 de noviembre, del Impuesto sobre Sociedades (LIS). En ella existe un régimen fiscal especial a favor de sociedades que tengan como actividad económica principal el arrendamiento de viviendas situadas en territorio español que hayan construido, promovido o adquirido (arts. 48 y 49 de la LIS), pero aplicable sólo en caso de que tales sociedades se dediquen al arrendamiento de viviendas incluidas en la LAU, que cumplan los requisitos y condiciones establecidos en dicha Ley, que cómo ya sabemos excluye a las viviendas de uso temporal turístico. El Impuesto sobre la Renta de los No Residentes se regula por el Real Decreto Legislativo 5/2004, de 5 de marzo, por el que se aprueba su texto refundido.

${ }^{17}$ Conforme al art. 29. 1. LIS, el tipo general de gravamen para los contribuyentes de este Impuesto será el 25 por ciento. No obstante, las entidades de nueva creación que realicen actividades económicas tributarán, en el primer período impositivo en que la base imponible resulte positiva y en el siguiente, al 


\subsection{Portugal}

\subsubsection{Regulación jurídica sectorial}

En Portugal la figura del alojamento local fue establecido por el Decreto-Ley 39/2008, de 7 de marzo, modificado por los Decretos-Leyes 228/2009 de 14 de septiembre y 15/2014 de 23 de enero, para permitir la prestación de servicios de alojamiento temporal en establecimientos que no reúnen los requisitos legalmente exigidos para los emprendimientos turísticos.

Esta realidad seria regulada por la Ordenanza (Portaria) 517/2008, de 25 de junio, posteriormente modificada por la Ordenanza (Portaria) 138/2012, de 14 de mayo, tras la transposición de la Directiva 2006/123/ CE del Parlamento Europeo y del Consejo, de 12 de diciembre de 2006, y por el Decreto-Ley 92/2010, de 26 de julio, que consagra la posibilidad de inscripción de los establecimientos de alojamiento local a través del Balcón Único Electrónico.

La Ordenanza (Portaria) 517/2008, de 25 de junio, prevé tres tipos de establecimientos de alojamiento local: a saber, el apartamento, la moradia y los estabelecimentos de hospedagem, estableciendo requisitos mínimos de seguridad e higiene.

Con la referida Ordenanza se buscaban dos objetivos: por un lado, enmarcar una serie de realidades que ofrecían servicios de alojamiento a turistas al margen de la ley; por otro, intentar regularizar algunos emprendimientos extintos por el Decreto-Ley 39/2008, de 7 de marzo (por ejemplo, pensiones, moteles, albergues y posadas) que no reunían condiciones para ser emprendimientos turísticos, y ello para que pudieran seguir prestando servicios de alojamiento y evitar su cierre.

Sin embargo, la dinámica del mercado de la demanda y oferta del alojamiento ha hecho surgir y proliferar un conjunto de nuevas realidades de alojamiento formalmente equiparables a las previstas en la Ordenanza (Portaria) 517/2008, de 25 de junio, que por su importancia turística y su evidente relevancia fiscal ha obligado no sólo a realizar una actualización del régimen jurídico aplicable a todo el fenómeno del alojamiento local, sino también a la creación de un régimen jurídico propio, que dé cuenta de esta circunstancia.

De este modo, ha sido el Decreto-Ley 15/2014, de 23 de enero, ${ }^{18}$ quien asumió la necesidad de autonomizar la figura del alojamento local para adaptar mejor a la realidad la reciente experiencia de esta figura en el panorama de la oferta de servicios de alojamiento. Y así, el Decreto-Ley 128/2014, de 29 de agosto, elevó la figura del alojamento local de categoría residual a categoría autónoma, reconociendo su relevancia turística e inaugurando un tratamiento jurídico propio.

De esta forma, las figuras de los emprendimentos turísticos y del alojamento local han pasado a ser dos figuras autónomas, imposibilitando el tratamiento conjunto y la equiparación bajo la figura y régimen del alojamento local de aquellos otros emprendimientos que cumplen con los requisitos para ser considerados como emprendimentos turísticos. Este tratamiento

tipo del 15 por ciento, excepto si, de acuerdo con lo previsto en este artículo, deban tributar a un tipo inferior. Por lo demás, la LIS prevé concretos beneficios fiscales para las entidades de pequeña y mediana dimensión (arts. 102 a 105,) que podrían ser aplicados de revestir tal forma las entidades titulares de los inmuebles alquilados (importe neto de la cifra de negocios habida en el período impositivo inmediato anterior sea inferior a 10 millones de euros, y no tener la consideración de entidad patrimonial). Respecto a los condicionamientos fiscales a la expansión turística (Enciso. 2006).

${ }^{18}$ El cual procedió a la segunda modificación del régimen jurídico de la instalación, explotación y funcionamiento de los emprendimientos turísticos, aprobado por el Decreto-Ley 39/2008, de 7 de marzo, que había sido previamente modificado por el Decreto-Ley 228 / 2009, de 14 de septiembre. 
diferenciado pretende garantizar que a realidades distintas se apliquen regímenes jurídicos distintos.

Conforme a la regulación actual se distinguen cuatro tipologías de alojamento local (la moradia, el apartamento, los estabelecimentos de hospedagem y quartos), ${ }^{19}$ habiéndose producido importantes modificaciones en la caracterización de los tres últimos.

Así, en el caso de los estabelecimentos de hospedagem cuyo régimen fue actualizado por el Decreto-Ley 128/2014, de 29 de agosto, y posteriormente por la Ley 62/2018, de 22 de agosto, se prevén requisitos particulares para los hostels, para los que se exigen características especiales. Sin entrar en detalles que impidan el desarrollo e innovación del producto, se buscó sobre todo enmarcar jurídicamente y preservar una figura que se impuso turísticamente. ${ }^{20}$

En el caso de los apartamentos, una tipología cada vez más frecuente en el mercado turístico mundial, amplificada por la publicidad e intermediación digital, el Decreto-Ley 128/2014, de 29 de agosto ha mantenido un importante margen de oferta del servicio, eso sí enmarcando fiscalmente su explotación dentro del régimen de prestación de servicios de alojamiento, e impidiendo que dicha actividad se desarrolle en un contexto de evasión fiscal.

Por lo que respecta a los requisitos administrativos exigidos cabe destacar en lo que concierne a la seguridad contra riesgo de incendio que se han registrado nuevas especificidades para los establecimientos de alojamiento local con menos de 10 usuarios, estableciéndose concretos requisitos mínimos a observar. En lo que se refiere a las competencias de control y de aplicación de sanciones, las mismas se atribuyen a la Autoridad de Seguridad Alimentaria y Económica.

\subsubsection{Régimen tributario aplicable cuando se desarrolla por particulares residentes en Portugal}

La explotación de la actividad de alojamiento local cuando se desarrolla por particulares residentes en territorio nacional, cae en el ámbito de incidencia de la categoría B del Código del Impuesto sobre la Renta de las Personas Singulares (CIRS). En esta categoría la determinación de la renta imponible sigue el establecido en el artículo 28 del CIRS: enmarcando el régimen simplificado cuando el sujeto pasivo no haya obtenido más de 200.000 euros de renta bruta de esta categoría el año anterior; o por opción por las reglas de la contabilidad organizada. ${ }^{21}$

\footnotetext{
19 Se considera moradia el establecimiento de alojamiento local cuya unidad de alojamiento está constituida por un edificio autónomo, de carácter unifamiliar. Se considera apartamento el establecimiento de alojamiento local cuya unidad de alojamiento está constituida por una fracción autónoma de edificio o parte de un edificio urbano susceptible de utilización independiente. Se considerará estabelecimento de hospedagem el establecimiento de alojamiento local cuyas unidades de alojamiento están constituidas por habitaciones, integradas en una fracción autónoma de edificio, en un edificio urbano o en una parte de edificio urbano susceptible de utilización independiente. Se considera quarto la explotación de alojamiento local efectuada en la residencia del arrendador, que corresponde a su domicilio fiscal, siendo la unidad de alojamiento la habitación y sólo siendo posible, en esta modalidad, tener un máximo de tres unidades, (véanse los apartados 2 a 4 del artículo 3 del DecretoLey 128/2014, de 29 de agosto, con la redacción que le fue dada por la Ley 62/2018, de 22 de agosto). Vide también Nóbrega (2018).

${ }^{20}$ Vide también Direção de Valorização da Oferta - Turismo de Portugal I. P. (2018, outubro).

${ }^{21}$ Vide también Costa (2018).
} 
El apartado $14^{22}$ del artículo 28 del CIRS permite que los titulares de ingresos de la explotación de establecimientos de alojamiento local en la modalidad de moradia o apartamento puedan optar, cada año, por la tributación de acuerdo con las reglas establecidas para la categoría $\mathrm{F}^{23}$ (Tiago, 2017).

En el presente artículo se refiere tan sólo por razones de limitación la regulación en caso de imposición en régimen simplificado. Así, el artículo 31 del CIRS define que la renta recaudada en régimen simplificado en el caso de alojamiento local se determinará sobre la base de la aplicación de un coeficiente sobre los rendimientos de prestaciones de servicios. Este coeficiente será de $0,15^{24}$ si se trata de "prestaciones de servicios efectuados en el ámbito de actividades de restauración y bebidas y de actividades hoteleras y similares" que se desarrollen en el ámbito de la actividad de explotación de establecimientos de alojamiento local en la modalidad de establecimento de hospedagem, y de 0,35 si es en la modalidad de moradia o apartamento. Para el período de imposición iniciado en 2018, el valor resultante de la aplicación del coeficiente de 0,35 se añadirá a la diferencia positiva derivada del apartado $13^{25}$ del artículo 31 del CIRS, cuando se trate de rendimientos de la explotación de establecimientos de alojamiento local en la modalidad de moradia o apartamento.

Se prevé la posibilidad de que el contribuyente pueda optar por cuantificar los rendimientos obtenidos según las normas de los rendimentos prediais, aunque sigan calificándose como de actividad económica, pudiendo aplicarse en este caso sobre ellos un tipo impositivo fijo (taxa) del 28 por ciento. La tributación en IRC se realizará conforme a los criterios referidos, sin embargo, el coeficiente aplicable en régimen simplificado a los

\footnotetext{
${ }^{22}$ Añadido por la Ley 42/2016, de 28 de diciembre.

${ }^{23}$ Como rendimientos prediales, para los cuales el ingreso a tributar se determina por deducción al valor bruto de las rentas recibidas o puestas a disposición, de los gastos efectivamente soportados y pagados por el sujeto pasivo para obtener o garantizar tales rendimientos, con las limitaciones previstas en el artículo 41 del CIRS.

${ }^{24}$ Redacción de la Ley 42/2016, de 28 de diciembre.

25 " 13 -A dedução ao rendimento que decorre da aplicação dos coeficientes previstos nas alíneas b) e c) do n. 1 está parcialmente condicionada à verificação de despesas e encargos efetivamente suportados, acrescendo ao rendimento tributável apurado nos termos dos números anteriores a diferença positiva entre $15 \%$ dos rendimentos brutos das prestações de serviços previstas naquelas alíneas e o somatório das seguintes importâncias: a) Montante de dedução específica previsto na alínea a) do n. 1 do artigo $25 .^{\circ}$ ou, quando superior, os montantes comprovadamente suportados com contribuiçóes obrigatórias para regimes de proteção social, conexas com as atividades em causa, que não sejam dedutíveis nos termos do n. ${ }^{\circ}$; b) Despesas com pessoal e encargos a título de remunerações, ordenados ou salários, comunicados pelo sujeito passivo à Autoridade Tributária e Aduaneira nos termos previstos na alínea c) do n. ${ }^{\circ} 1$ do artigo 119. ${ }^{\circ}$; c) Rendas de imóveis afetas à atividade empresarial ou profissional que constem de faturas e outros documentos, comunicados à Autoridade Tributária e Aduaneira, nos termos previstos no n. ${ }^{\circ} 2$ do artigo $78 .^{\circ}-E ;$ d) $1,5 \%$ do valor patrimonial tributário dos imóveis afetos à atividade empresarial ou profissional ou, quanto aos imóveis afetos a atividades hoteleiras ou de alojamento local, 4 \% do respetivo valor patrimonial tributário, de que o sujeito passivo seja o proprietário, usufrutuário ou superficiário; e) Outras despesas com a aquisição de bens e prestações de serviços relacionadas com a atividade, que constem de faturas comunicadas à Autoridade Tributária e Aduaneira nos termos do Decreto-Lei 198/2012, de 24 de agosto, ou emitidas no Portal das Finanças, nos termos da alínea a) do n. ${ }^{\circ} 1$ do artigo $115^{\circ}$, designadamente despesas com materiais de consumo corrente, eletricidade, água, transportes e comunicações, rendas, contencioso, seguros, rendas de locação financeira, quotizações para ordens e outras organizações representativas de categorias profissionais respeitantes ao sujeito passivo, deslocações, viagens e estadas do sujeito passivo e dos seus empregados; f) Importações ou aquisições intracomunitárias de bens e serviços relacionados com a atividade" (N. ${ }^{\circ}$ aditado por la Ley 114/2017, de 29 de diciembre).
} 
establecimientos de alojamiento es de 0,04, aplicándose el tipo impositivo proporcional concretado por la normativa (21 por ciento).

El régimen previsto conlleva el cumplimiento de una serie de obligaciones, de modo que en caso de incumplimiento de las obligaciones fiscales derivadas de la actividad ejercida en virtud del Régimen Jurídico del Alojamiento Local se cometerá una infracción tributaria, en los términos previstos en el Régimen General de las Infracciones Tributarias, aprobado por la Ley 15/2001, de 5 de junio.

\subsection{Semejanzas y diferencias}

El alojamiento temporal turístico privado en Portugal y España presenta importantes diferencias de detalle tanto en su regulación sectorial como tributaria, pese a responder a la misma necesidad: la mejora en la ordenación de un sector específico de actividad económica y el afloramiento de rentas sumergidas.

En Portugal se regula el alojamiento temporal turístico privado en una única norma para todo el Estado, el Decreto-Ley 128/2014, a través de un concepto aglutinador denominado alojamento local que distingue y caracteriza cuatro categorías diferenciadas de hospedaje: moradias, apartamento, estabelecimento de hospedagem y quarto. En España no existe una única regulación sino hasta la fecha, 14 regulaciones autonómicas ya aprobadas, y 3 pendientes de aprobación, que contemplan con diferente denominación este tipo de alojamientos, siendo el más frecuente el de "vivienda de uso turístico", previéndose en cada una de ellas no sólo diferentes requisitos referidos a las exigencias que debe reunir el propio inmueble sino a las propias obligaciones de tramitación, comercialización o explotación de éstos. El régimen jurídico portugués de este tipo de alojamientos destacaría por su cohesión, mientras el español lo haría por su falta de homogeneidad, faltando al cumplimiento del principio de unidad de mercado en la normativa turística que les afecta.

El régimen tributario previsto tanto en Portugal como en España plantea cálculos de gravamen diferenciados según la naturaleza jurídica del titular del inmueble y su residencia efectiva. De este modo, si el cedente del uso del inmueble para alojamiento temporal turístico es persona física (pessoa singular) con residencia efectiva en cada país, la tributación se efectuará en el Impuesto sobre la Renta de las Personas Físicas (IRPF) español, o el Imposto sobre Rendimentos das Pessoas Singulares (IRS) portugués. Si el cedente fuese persona jurídica (pessoa coletiva) con residencia efectiva en cada país, la tributación se efectuará en el Impuesto sobre Sociedades (IS) español, o en el Imposto sobre Rendimentos das Pessoas Coletivas (IRC) portugués. Si el cedente fuese no residente en estos países, pero obtuviese rentas en ellos derivadas de la explotación o el arrendamiento de estos alojamientos, la regulación en ese caso varía: aplicándose un único impuesto en España con independencia de la naturaleza jurídica del titular, el Impuesto sobre la Renta de los No Residentes (IRNR); mientras que en Portugal la tributación se efectuará en el Imposto sobre o Rendimento das Pessoas Coletivas (IRC) si la explotación de la actividad se realiza por una persona jurídica (persona coletiva) o en el Imposto sobre o Rendimento das Pessoas Singulares (IRS) si es persona física (pessoa singular), con formas de cálculo del tributo de modo distinto de los residentes.

Los rendimientos derivados de la explotación o el arrendamiento de estos alojamientos tributan conforme a una regulación específica en la normativa tributaria portuguesa, mientras 
en España carecen de especificidad tributaria, resultándoles de aplicación el régimen normal de tributación aplicable a los demás rendimientos de su misma calificación jurídica.

En el IRS portugués, los rendimientos derivados de la explotación o el arrendamiento de los alojamientos locales por personas físicas o singulares son calificados siempre como de Categoría $\mathrm{B},{ }^{26}$ cuantificándose por la diferencia entre los ingresos íntegros obtenidos y los gastos aplicables si optan por la contabilidad organizada o por aplicación a los rendimientos brutos de los coeficientes de 0,15 (si establecimento de hospedagem) o 0,35 (si moradia o apartamento), encuadrándose en el régimen simplificado. Para las moradias y apartamentos, hasta 2017, los gastos deducibles resultaban de la aplicación del coeficiente fijo del 0,35 por ciento sobre los ingresos, lo que suponía aceptar de forma indirecta el 65 por ciento de costes de la actividad. Desde 2018 existen reglas limitadoras de las deducciones en la tipología de moradia y apartamento.

La normativa del impuesto también prevé la posibilidad de que el contribuyente pueda optar por cuantificar los rendimientos obtenidos según las normas de los rendimentos prediais aunque sigan calificándose como de actividad económica, pudiendo aplicarse en este caso sobre ellos un tipo impositivo fijo (taxa) del 28 por ciento. La tributación en IRC se realizará conforme a los criterios referidos, sin embargo, el coeficiente aplicable en régimen simplificado a los establecimientos de alojamiento es de 0,04, aplicándose el tipo impositivo proporcional concretado por la normativa (21 por ciento).

En el IRPF español tales rendimientos carecen de especificidad por el hecho de provenir de bienes destinados a un uso turístico, pudiéndose calificar y cuantificar como los demás rendimientos de capital inmobiliario o bien de actividad económica previstos en la normativa, según el titular del inmueble se limite simplemente a la cesión temporal del uso del inmueble o bien preste además de ello servicios adicionales similares a los de los establecimientos hoteleros. Serán también rendimientos de actividad económica si se ha contratado a una persona a tiempo completo y con contrato laboral para que se encargue de la realización de esta actividad. Su cuantificación se efectuará según las reglas generales de cálculo de tales rendimientos en estimación directa normal o simplificada previstas en la normativa del IRPF y en su caso del IS.

\section{Estudio de caso: Tributación de un inmueble destinado a alojamiento turístico}

Para ilustrar algunas de las diferencias de tributación entre España y Portugal realizaremos a continuación un estudio de caso limitado a contemplar una de las hipótesis más habituales en los dos países, dadas las limitaciones de extensión del propio trabajo, referido al gravamen que soportará el titular de un inmueble, persona física residente que lo alquila para obtener rentas adicionales. Tomamos como presupuesto un sujeto pasivo residente ${ }^{27}$ que obtiene rendimientos de trabajo dependiente y simultáneamente explota un establecimiento de alojamiento local en la modalidad de vivienda. En el caso español con residencia en la Región de Murcia. En el caso portugués con dos hipótesis: 1 - tributación según las reglas del régimen simplificado; 2 - con opción de tributación de acuerdo con las reglas de los rendimientos prediales. Datos reportados al año 2018.

\footnotetext{
${ }^{26}$ Vide también Ordem dos Contabilistas Certificados (2018).

${ }^{27}$ A propósito de la tributación de los no residentes recomendamos consulta de Silva (2018).
} 


\subsection{Conforme al régimen tributario español}

Cuadro 1. Determinación de la Base Liquidable (2018)

\begin{tabular}{|c|c|c|c|}
\cline { 2 - 4 } \multicolumn{1}{c|}{} & Rendimiento bruto & Deducciones & Base Liquidable \\
\hline Trabajo Dependiente & $(1) 21000,00$ & $(2)-5500,00$ & $\mathbf{1 5 5 0 0 , 0 0}$ \\
\hline Rendimiento Capital Imobiliário (RCI) & $(3) 20987,50$ & $(4)-2900,00$ & $\mathbf{1 8 0 8 7 , 5 0}$ \\
\hline Imputación Renda Imobiliário (IRI) & & & $(5) \mathbf{1 6 0 0 , 0 0}$ \\
\hline \multicolumn{3}{|l}{} & $\mathbf{3 5 1 8 7 , 5 0}$ \\
\hline
\end{tabular}

(1) Base $1.500 / \mathrm{mes}$

(2) Fijo $€ 2.000$ + Seguridad Social estimado $€ 3.500$

(3) €115/noche * 6 meses ocupación

(4) Considerando inmueble no hipotecado; IBI estimado $€ 500$ una vez que varía de municipio a municipio; Depreciación inmueble [3\% (V Cadastral o V Adquisición)] * \% ocupación; Valor Catastral = Valor Adquisición $=€ 160.000$

(5) $2 \%$ * Valor Cadastral *\% no ocupada.

Cuadro 2. Cálculo de la Cuota (Estatal + Autonómica, Región de Murcia) (2018)

Un: euros

\begin{tabular}{|l|r|}
\hline \multicolumn{2}{|c|}{$\begin{array}{c}\text { Cuota Íntegra Estatal Previa } \\
\text { Escala de Gravamen } \\
\text { Estatal }\end{array}$} \\
\hline Hasta 20200,00 & 2112,75 \\
\hline Resto $\quad 14987,50 \quad 15 \%$ & 2248,13 \\
\hline & 4360,88 \\
\hline
\end{tabular}

\begin{tabular}{|c|c|c|c|}
\hline \multicolumn{4}{|c|}{$\begin{array}{l}\text { Cuota Íntegra Autonómica Previa } \\
\text { Escala de Gravamen Región de } \\
\text { Murcia }\end{array}$} \\
\hline Hasta & 20200,00 & & 2213,75 \\
\hline \multirow[t]{2}{*}{ Resto } & 14987,50 & $15,5 \%$ & 2323,06 \\
\hline & & & 4536,81 \\
\hline
\end{tabular}

\subsection{Conforme al régimen tributario portugués}

Cuadro 3. Cálculo Rendimiento Liquidable y Cuota: Hip. 1 (2018)

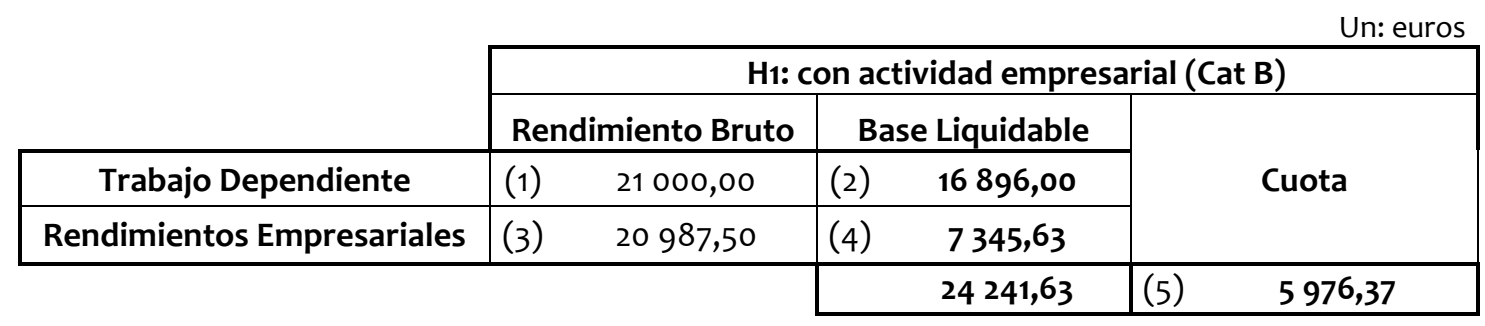

(1) Base $€ 1.500 / \mathrm{mes}$

(2) Después deducción específica de los ingresos de trabajo dependiente (cf. art. ${ }^{\circ} 25 .^{\circ} \mathrm{CIRS}$ )

(3) €115/noche * 6 meses ocupación.

(4) Asumiendo que de la aplicación del apartado 13 del artículo 31 no resulta valor a crecer a la aplicación del coeficiente de al. c) del apartado 1 del artículo $31 \mathrm{CIRS}$

(5) Se aplica el $4^{\circ}$ escalón de grabado cf. artículo 68 del CIRS al que corresponde $35 \%$ 
Cuadro 4. Cálculo Rendimiento Liquidable y Cuota: Hip. 2 (2018)

Un: euros

\begin{tabular}{|l|lr|r|r|r|r|}
\cline { 2 - 7 } \multicolumn{1}{c|}{} & \multicolumn{4}{c|}{ H2: AL opta por Cat. F con tributación autónoma } \\
\cline { 2 - 7 } \multicolumn{1}{c|}{} & Rendimiento Bruto & \multicolumn{2}{c|}{ Base Liquidable } & \multicolumn{2}{c|}{ Cuota } \\
\hline Trabajo Dependiente & $(1)$ & 21000,00 & $(2)$ & $\mathbf{1 6 8 9 6 , 0 0}$ & $(3)$ & $\mathbf{3 6 2 4 , 1 2}$ \\
\hline Rendimientos Prediales & $(4)$ & 20987,50 & $(5)$ & $\mathbf{1 8 ~ 8 8 8 , 7 5}$ & $(6)$ & $\mathbf{5 2 8 8 , 8 5}$ \\
\hline
\end{tabular}

(1) Base $€ 1.500 /$ mes

(2) Después deducción específica de los ingresos de trabajo dependiente (cf. art. ${ }^{\circ} 25 .^{\circ} \mathrm{CIRS}$ )

(3) Por aplicación del $3^{\circ}$ escalón de grabado cf. artículo 68 del CIRS al que corresponde 28,5\%

(4) $€ 115 /$ noche * 6 meses ocupación

(5) Asumiendo deducciones específicas de la Categoría F cf. art. $470^{\circ}$ do CIRS (IMI; gastos de conservación y reparación del inmueble $=€ 2.098,75)$

(6) Por aplicación de la tasa de tributación autónoma del $28 \%$ (cf. al. e) n. ${ }^{\circ} 2$ art. $^{\circ} 72 .{ }^{\circ} \mathrm{CIRS}$ )

\subsection{Tributación en España versus Portugal para el estudio de caso}

Cuadro 5. Resumen hipótesis más favorable para los contribuyentes

Un: euros

\begin{tabular}{|l|r|r|r|}
\multicolumn{3}{c|}{} & \multicolumn{2}{c|}{ Un: euros } \\
\cline { 2 - 4 } \multicolumn{1}{c|}{} & Rendimiento Bruto & Base Liquidable & Cuota Total \\
\hline España & 41987,50 & $\mathbf{3 5 1 8 7 , 5 0}$ & $\mathbf{8 8 9 7 , 6 9}$ \\
\hline Portugal (H1-Rendimientos Empresariales: RS) & 41987,50 & $\mathbf{2 4 2 4 1 , 6 3}$ & $\mathbf{5 9 7 6 , 3 7}$ \\
\hline Portugal (H2-Rendimientos Prediales) & 41987,50 & $\mathbf{3 5 7 8 4 , 7 5}$ & $\mathbf{8 9 1 2 , 9 7}$ \\
\hline
\end{tabular}

Tomando como presupuestos los indicados en 3 para nuestro estudio de caso constatamos que, para el mismo nivel de rendimiento bruto los rendimientos provenientes del alojamiento local generan una cuota total menor en España si se consideran rendimientos prediales (en Portugal). Sin embargo, se estará generando una reducción sustancial tanto en la base liquidable tanto la cuota total para el caso portugués si se grava como ingresos empresariales en la opción de régimen simplificado.

\section{Conclusiones: ¿Es la regulación fiscal en estos países un factor teórico de estímulo de determinadas conductas?}

Los regímenes jurídicos generales y fiscales en España y Portugal del alojamiento temporal turístico privado tienen más diferencias que similitudes. Esto se debe esencialmente al hecho de que en España no existe una única regulación sino hasta la fecha, 14 regulaciones autonómicas ya aprobadas, y 3 pendientes de aprobación, que contemplan con diferente denominación y caracterización este tipo de alojamientos. Desde el punto de vista tributario las normas de determinación del ingreso imponible y de la respectiva cuota son también muy distintas en los dos países, con una regulación específica en Portugal, y ninguna especificidad en España respecto a otras rentas de la misma calificación tributaria. 
El caso estudiado de un sujeto pasivo residente persona física que obtuviese en 2018 rendimientos del trabajo dependiente de $€ 21.000$ euros, y que explotara como propietario una vivienda para fines turísticos obteniendo de esa actividad el valor anual de $€ 20.987,50$, permite evidenciar que en España soportaría una cuota total de $€ 8.897,69$, mientras que en Portugal la opción más ventajosa sería gravar como ingresos empresariales según las normas del régimen simplificado a la que corresponde una cuota de $€ 5 \cdot 976,37$. En el presente caso, a pesar de que en Portugal es posible optar por la tributación como ingresos prediales a una tasa inferior, la base imponible sería mayor por lo que esta opción no sería fiscalmente ventajosa.

Así se concluye que conforme al supuesto planteado se evidencia que existe una ventaja fiscal para los contribuyentes residentes en Portugal, al preverse una cuantía de gastos mayor. En cualquier caso, también se ha de destacar que en ambos países la carga fiscal a cuenta de un individuo que desarrolla la actividad de alojamiento temporal turístico en la modalidad de vivienda siempre va a depender de la cuantía de otros ingresos sujetos a agregación en IRPF (España) o IRS (Portugal), al tratarse de impuestos progresivos y resultar similar su método de cálculo.

De acuerdo con todo lo expuesto podemos efectuar una serie de consideraciones. La regulación del alojamiento privado temporal a turistas viene condicionada de forma extraordinaria en sus aspectos sectoriales de carácter administrativo por el entorno en donde se lleve a cabo. Así, en España se encuentran situaciones diferenciadas por Comunidad Autónoma, en las que se especifican realidades distintas respecto al propio objeto de regulación ("vivienda de uso turístico", "viviendas vacacionales” o "viviendas turísticas”), así como con relación a otras cuestiones tales como: la posibilidad de cesión total o parcial del inmueble; en todo tipo de viviendas o sólo en determinadas; la posibilidad de explotación por el propietario, por un tercero o por una empresa; o sus limitaciones respecto a la duración mínima o máxima de la estancia, todo ello sin perjuicio de las importantes diferencias respecto a otras cuestiones relevantes como su clasificación, el régimen sancionador, o las distintas exigencias en aspectos de tramitación, comercialización o explotación de las viviendas. En Portugal, existe por el contrario una sola regulación dada su estructura territorial y normativa, si bien es cierto que ello está generando ciertos problemas de aplicación, necesitando de su adecuación en determinados aspectos a la realidad de cada municipio, tal y como ya se está efectuando. Constituyendo un fenómeno de crecimiento y perfiles diversos según la zona en que se desarrolle y el nivel de expansión turística que ésta tenga, la realidad nos demuestra una vez más como la regulación normativa trata de adaptarse a las circunstancias que van surgiendo, quedando en este caso absolutamente condicionada por el fin que se pretenda de limitación o crecimiento de tales actuaciones particulares.

Llegados a este punto, ¿puede considerarse la fiscalidad como un elemento de impulso o de limitación de los alquileres turísticos en los dos países? En España no hay ningún tratamiento específico y diferencial de la fiscalidad de los alquileres temporales de uso turístico que puede llevarnos a hablar de estímulo de determinadas conductas relacionadas con éste. Por el contrario, tales rentas no pueden disfrutar de las reducciones aplicables a otros rendimientos derivados del arrendamiento (por ejemplo, por rentas generadas en periodo superior a dos años, o de alquiler para vivienda habitual), estando sujetas a la progresividad que les corresponda en el IRPF al tributar junto a otro tipo de rentas como las de trabajo o actividades económicas, o al tipo impositivo general del IS sin deducción alguna o trato diferencial, debiendo además soportar en algunos casos otros gravámenes específicos derivados de la 
explotación turística (tasa turística). La fiscalidad no actúa en España como condicionante directo de estímulo. En Portugal por el contrario sí existe una regulación fiscal específica en materia de alquileres turísticos, resultando ventajosa en determinadas hipótesis con respecto a la tributación que soportarían otros rendimientos, en caso de ser considerados como ingresos empresariales de régimen simplificado, aunque no tanto cuando sean considerados como ingresos prediales. En Portugal, y quizá por tratarse de actuaciones aun en crecimiento generalizado, la fiscalidad sí se ha empleado hasta la fecha, eso sí con limitaciones, como un cierto instrumento de estímulo de comportamientos específicos.

\section{Referências}

Asociación Española de Contabilidad y Administración de Empresas (AECA) (2014). Régimen jurídico de las empresas de alojamiento turístico en España y Portugal, Documento n ${ }^{\circ}$. 2: 1-165.

Costa, E. M. (2018, 03 setembro). Alojamento local qualificação do rendimento, Jornal de Negócios, p. 29.

Direção de Valorização da Oferta - Turismo de Portugal I. P. (2018, outubro). Alojamento local regime jurídico, guia técnico da direção de valorização da oferta. Lisboa: Turismo de Portugal.

Enciso de Izaguirre, V. (2006). Barreras fiscales al turismo residencial (crónica tributária, n. ${ }^{\circ} 118$ ). Madrid: Instituto de Estudios Fiscales: 37-54.

Herrero, C. (2017). Las viviendas de uso turístico: ¿El enemigo a abatir? Reflexiones sobre la normativa autonómica en materia de alojamientos turísticos. Revista de Estudios Europeos, 70, 147-158.

Martín-Faba, J. M. (2016). Impulso judicial al turismo colaborativo. Revista CESCO de Derecho de Consumo, $18,113-127$.

Nóbrega, A. (2018). Novo regime jurídico da exploração dos estabelecimentos de alojamento local Anotado e comentado. Albufeira: Arandis.

Ordem dos Contabilistas Certificados (2018, 01 abril). PT20596 - IRS - Regime simplificado (alojamento local). [Parecer técnico publicado no portal da Ordem dos Contabilistas Certificados].

Organización Mundial del Turismo (2008). Recomendaciones sobre estadísticas de turismo. (Serie M N.º 83). Nueva York: Departamento de Información Económica y Social y Análisis de Políticas, División de Estadística y Informes Estadísticos.

Recio-Ramírez, M. A. (2016). Aproximación a la tributación del llamado turismo 2.0 en España, en especial las viviendas de uso turístico. International Journal of Scientific Management and Tourism, 2(4), 207-225.

Román. I. M., Pavlova, N., Nieto, J. L. \& Bonillo, D. (2017). La legislación sobre los apartamentos turísticos y viviendas de uso turístico en España, comparativa por Comunidades Autónomas. International Journal of Scientific Management and Tourism, 3-4, 397-417.

Ruíz, M. (2017). La economía colaborativa en el ámbito de la vivienda: Cuestiones fiscales pendientes. Revista Jurídica de los Derechos Sociales, Lex Social, 7(2), 53-76.

Silva, A. C. (2018, 24 julho). O alojamento local e as plataformas digitais. Jornal de Negócios, p. 26.

Tiago, L. (2017, 20 março). Alojamento local escolhe tributação. Jornal de Notícias, p. 11.

Verdera, B. (2009). El arrendamiento de temporada frente a las estâncias turísticas en viviendas. Consultor Inmobiliario, 107, 3-19.

\section{Referências normativas}

\section{España}

- Ley $4 / 2013$, de 4 de junio, de medidas de flexibilización y fomento del mercado del alquiler de viviendas.

- Ley 29/1994, de 24 de noviembre, Ley de Arrendamientos Urbanos.

- Normativas autonómicas de turismo. 


\section{Portugal}

- Lei n. ${ }^{\circ}$ 62/2018 de 22 agosto. Diário da República n. ${ }^{\circ}$ 161/2018 - Série I. Assembleia da República. Lisboa.

- Lei n. ${ }^{\circ}$ 114/2017, de 29 de dezembro. Diário da República n. ${ }^{\circ}$ 249/2017- I Série. Assembleia da República. Lisboa.

- Lei n. ${ }^{\circ}$ 42/2016 de 28 de dezembro. Diário da República n. ${ }^{\circ}$ 248/2016 - I Série. Assembleia da República. Lisboa.

- Decreto-Lei 63/2015 de 23 de abril. Diário da República n. 79/2015 - I Série. Ministério da Economia. Lisboa.

- Decreto-Lei 128/2014 de 29 de agosto. Diário da República n. ${ }^{\circ}$ 166/2014 - I Série. Ministério da Economia. Lisboa;

- Decreto-Lei 15/2014 de 23 de janeiro. Diário da República n. º 16/2014- I Série. Ministério da Economia. Lisboa.

- Portaria n. ${ }^{\circ}$ 138/2012 de 14 de maio. Diário da República n. ${ }^{\circ}$ 93/2012 - I Série. Presidência do Conselho de Ministros e Ministério da Economia e do Emprego. Lisboa

- Decreto-Lei 228/2009 de 14 de setembro. Diário da República n. ${ }^{\circ}$ 178/2009 - I Série. Ministério da Economia e da Inovação. Lisboa

- Decreto-Lei 39/2008 de 7 de março. Diário da República n. ${ }^{\circ}$ 48/2008 - I Série. Ministério da Economia e da Inovação. Lisboa.

- Portaria n. ${ }^{\circ}$ 517/2008 de 25 de junho. Diário da República n. ${ }^{\circ}$ 121/2008 - I Série. Presidência do Conselho de Ministros e Ministério da Economia e da Inovação. Lisboa

- Decreto-Lei 442-A/1988 de 30 de novembro. Diário da República n. ${ }^{\circ}$ 277/1988, $10^{\circ}$ Suplemento - I Série. Ministério das Finanças. Lisboa

MARÍA DEL CARMEN PASTOR DEL PINO es doctora en Derecho por la Universidad de Murcia (Murcia, España). Profesora de Derecho Financiero y Tributario en la Universidad Politécnica de Cartagena (Cartagena, España). Líneas de investigación: políticas fiscales de fomento, legitimación, idoneidad y control en el empleo de incentivos fiscales. Dirección institucional: Departamento de Ciencias Jurídicas de la Facultad de Ciencias de la Empresa de la Universidad Politécnica de Cartagena. Facultad de Ciencias de la Empresa, Universidad Politécnica de Cartagena, Calle Real, 3, 30.201, Cartagena, Murcia, España.

MARIA DE LURDES FIGUEIRINHA VARELA es doutoranda en Administración. Mestre en Ciências Económicas y Empresariales. Profesora de Derecho Financiero y Tributario en la Universidade do Algarve-ESGHT (Faro, Portugal). Líneas de investigación: impacto de las políticas fiscales en la actividad turística, incentivos fiscales al turismo, derecho tributário en general. Dirección institucional: Escola Superior de Gestão, Hotelaria e Turismo da Universidade do Algarve, Campus da Penha, 8005-139 Faro, Portugal.

Submetido em 21 agosto 2018

Aceite em 28 fevereiro 2019 